\title{
Kernos
}

Revue internationale et pluridisciplinaire de religion grecque antique

32 | 2019

Varia

\section{Female Mobility and Gendered Space in Ancient Greek Myth}

Marie Augier

\section{(2) OpenEdition \\ Journals}

Édition électronique

URL : https://journals.openedition.org/kernos/3252

DOI : 10.4000/kernos.3252

ISSN : 2034-7871

\section{Éditeur}

Centre international d'étude de la religion grecque antique

\section{Édition imprimée}

Date de publication : 1 décembre 2019

Pagination : 352-354

ISBN : 978-2-87562-229-7

ISSN : 0776-3824

\section{Référence électronique}

Marie Augier, «Female Mobility and Gendered Space in Ancient Greek Myth », Kernos [En ligne], 32 |

2019, mis en ligne le 01 octobre 2019, consulté le 02 février 2022. URL : http://

journals.openedition.org/kernos/3252; DOI : https://doi.org/10.4000/kernos.3252

Ce document a été généré automatiquement le 2 février 2022.

Kernos 


\title{
Female Mobility and Gendered Space in Ancient Greek Myth
}

\author{
Marie Augier
}

\section{RÉFÉRENCE}

Ariadne KONSTANTINOU, Female Mobility and Gendered Space in Ancient Greek Myth, London/ New York, Bloomsbury, 2018. 1 vol. 16, $3 \times 24$ cm, 189 p. (Classical Studies Monographs). ISBN : 978-1-4742-5676-6.

1 Fruit d'une thèse de doctorat soutenue en 2013 , le petit ouvrage dont il est fait la recension revient sur la question de l'intersection entre genre et espace tel que l'avait fait Susan Guettel Cole en 2004. Ariadne Konstantinou se propose d'étudier la mobilité et le mouvement des déesses (Partie I) et des héroïnes (Partie II) dans les mythes, en les mettant en parallèle avec les femmes. La question est de savoir si cette mobilité avait ou non une connotation positive dans les pratiques discursives évoquées. Selon l'A., les mythes, qu'elle fait le choix de ne pas mettre en série, permettent d'aider à se représenter la mentalité grecque.

2 La première partie de son ouvrage évoque les déesses olympiennes Hestia, Athéna, Artémis, Aphrodite, Déméter et Héra en s'appuyant sur la poésie épique de la période archaïque et les hymnes homériques. À partir de l'Hymne à Aphrodite, elle distingue dans son volume les déesses "vierges ", celles qui ont refusé le mariage, des autres. Parmi les déesses "vierges", Hestia tient une place à part en raison de son absence de mobilité : attachée au foyer et à l'agora, elle est au centre des activités de la maison et de la polis. L'A. ne voit pas dans cette fixité d'Hestia un indice genré de l'absence de mouvement des femmes dans la maison, mais plutôt une marque de son caractère divin, justement parce qu'elle est au centre de toutes les activités humaines. Athéna est différente d'Hestia et des femmes, car en tant que guerrière et qu'Erganè, elle transcende les rôles genrés. Quant à la mobilité d'Artémis, elle est liée à l'espace de la chasse. 
3 Les déesses épouses et mères sont évoquées ensuite. Les mentions d'Aphrodite dans son hymne éponyme et dans l'Iliade en font une déesse mobile et active sexuellement ; qu'il s'agisse de sa relation avec Anchise ou de sa liaison avec Arès, Aphrodite quitte toujours rapidement le lieu de ses ébats. Déméter dans l'hymne qui lui est dédié est celle qui parcourt le monde à la recherche de sa fille, mais reste immobile lors de son séjour chez les mortels, telle la statue de la déesse dans son temple. Ici, l'A. fait un lien entre le choix de Déméter d'apparaître sous les traits d'une vieille femme et la liberté de mouvement attachée à cette catégorie d'âge. Héra, dans l'Iliade et dans les hymnes homériques est une déesse qui peut se montrer mobile, notamment lorsqu'elle séduit Zeus, mais qui, de manière générale, choisit de rester sur place. Cette fixité est comprise par l'A. comme un signe de pouvoir, une marque de sa stature royale. Toutes ces figures divines féminines ont, selon l'A., le point commun d'être aussi libres de leur mouvement que les figures masculines. Qu'elles choisissent de rester fixes ou de se déplacer, la mobilité des déesses est en tout cas selon elle bien liée à leur nature divine et non à leur genre. Sa conclusion est que le genre n'est pas déterminant dans le cas des mobilités divines. Celles-ci ne sont pas limitées dans leur déplacement en raison de leur sexe, car ce sont avant tout des déesses et non des femmes.

4 La seconde partie de son ouvrage évoque les héroïnes qui, selon l'A., ont une mobilité différente des déesses en raison de leur nature mortelle. Elle se demande si les descriptions spatiales dans les sources convoquées sont descriptives ou prescriptives ou les deux à la fois. La lecture des Suppliantes et du Prométhée enchainé lui permet d'évoquer le mouvement centrifuge opéré par les jeunes mariées qui quittent le foyer paternel pour rejoindre leur nouvel oikos. L'A. défend l'idée que ces mythes apportent des informations sur les valeurs sociales attachées aux femmes " réelles ». Les exemples d'Io et des Danaïdes sont convoqués, alors même que celles-ci opèrent deux types de mobilité : une lointaine vers une autre patrie et une proche liée au mariage; mais malgré tout, l'A. relie aussi bien les errances d'Io que le voyage des Danaïdes au départ de la maison paternelle tel qu'on le concevait dans la vision athénienne de la mobilité des filles, et ce même si la tentative des Danaïdes d'être intégrées à Argos, à l'Hellenikon, est présentée comme un mouvement centripète vers ce qui serait leur région d'origine.

Dans un second temps, l'A. se pose la question du lien entre les mythes et les rituels par un rappel des mythes évoquant les Ménades et les chasseresses à travers les Bacchantes d'Euripide et l'Hymne à Artémis de Callimaque. Elle se demande en particulier si les espaces où elles se meuvent peuvent être reliés à des pratiques rituelles. Le cas des Ménades quittant leur maison et la cité pour la montagne semble opposer deux espaces, mais, selon l'A., ces deux espaces deviennent en fait perméables par l'expérience dionysiaque. Les lieux ne sont pas pour elle genrés. L'espace dans lequel évoluent quant à elles les chasseresses est loin de la cité. Atalante et Cyrène s'éloignant du foyer paternel rejettent la sexualité, de même que Procris, mais ces tentatives s'avèrent vaines. Les cas de Callisto et d'Iphigénie sont ensuite mentionnés, l'A. se posant la question de leur lien avec les rites de Brauron sans parvenir à le démontrer. Finalement, le seul lien mis au jour par l'A. entre mythes et rituels serait celui du mouvement des Ménades hors de leur foyer qui représenterait les femmes sortant de la maison pour prendre part aux rituels.

6 Dans son dernier chapitre, l'A. convoque enfin l'image du «mur de verre », plutôt que celle du " plafond de verre ", pour parler de la limitation des espaces pour les héroïnes et, partant de là, des femmes grecques. La première expression lui semble plus 
pertinente pour mettre en lumière une limitation des mobilités des femmes plus horizontale que verticale. Ainsi les récits d'héroïnes quittant le foyer pour aller dans des espaces loin des activités civiques renverraient à ces « murs de verre » marquant une frontière avec certains espaces publics réservés aux hommes.

\section{AUTEURS}

\section{MARIE AUGIER}

Université de Strasbourg 